\section{"LA-UR-915 2772}

Title:

Author(s):

Submitted to:

A 329

08.11

\section{Mechanical Properties and Failure Mechanisms of Carbon Fiber Reinforced Epoxy Laminated Composites}

\section{W. Richards Thissell}

Anna K. Zurek

Frank Addessio

1995 APS Topical Conference Proceedings "Shock Compression of Condensed Matter-1995"

Aug. 14-18, 1995

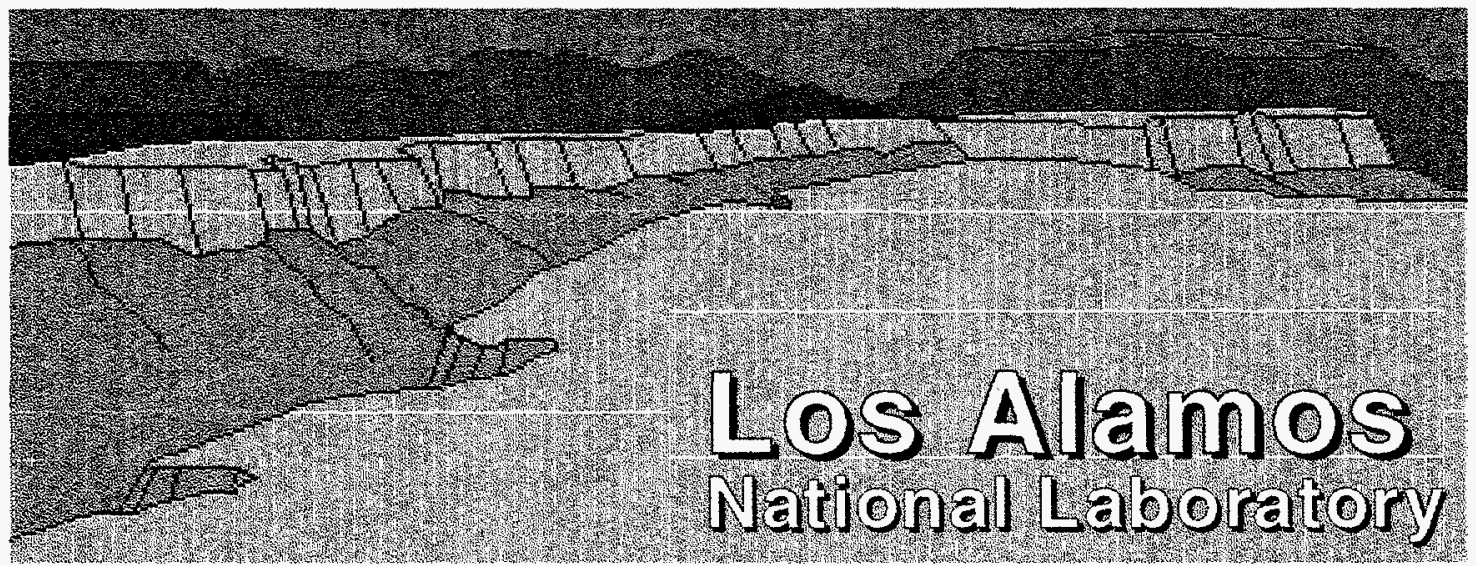

Los Alamos National Laboratory, an affirmative actioniequal opportunity employer, is operated by the University of California for the U.S. Department of Energy under contract W-7405-ENG-36. By acceptance of this article, the publisher recognizes that the U.S. Government retains a nonexclusive, royaltyfree license to publish or reproduce the published form of this contribution, or to allow others to do so, for U.S. Government purposes. The Los Alamos National Laboratory requests that the publisher identify this article as work performed under the auspices of the U.S. Department of Energy.

This is a preprint of a paper intended for publication in a journal or proceedings. Because changes may be made before publication, this preprint is made available with the understanding that it will not be cited or reproduced without the permission of the author. 


\section{DISCLAIMER}

This report was prepared as an account of work sponsored by an agency of the United States Government. Neither the United States Government nor any agency thereof, nor any of their employees, make any warranty, express or implied, or assumes any legal liability or responsibility for the accuracy, completeness, or usefulness of any information, apparatus, product, or process disclosed, or represents that its use would not infringe privately owned rights. Reference herein to any specific commercial product, process, or service by trade name, trademark, manufacturer, or otherwise does not necessarily constitute or imply its endorsement, recommendation, or favoring by the United States Government or any agency thereof. The views and opinions of authors expressed herein do not necessarily state or reflect those of the United States Government or any agency thereof. 


\section{DISCLAIMER}

Portions of this document may be illegible in electronic image products. Images are produced from the best available original document. 


\title{
MECHANICAL PROPERTIES AND FAILURE MECHANISMS OF CARBON FIBER REINFORCED EPOXY LAMINATED COMPOSITES
}

\author{
W. Richards Thissell, Anna K. Zurek, and Frank Addessio* \\ Materials Research and Processing Science, MS: G755 \\ *Fluid Dynamics, MS: B216 \\ Los Alamos National Laboratory \\ Los Alamos NM 87545
}

\begin{abstract}
The mechanical behavior of quasi-isotropic and unidirectional epoxy-matrix carbon-fiber laminated composites subjected to compressive loading at strain rates of $10^{-3}$ and $2000 \mathrm{~s}^{-1}$ are described. Failure in the studied composites was dominated by delamination which proceeded by brittle fracture of the epoxy-matrix. The matrix-fiber bonding in these composites is very strong and prevented the occurrence of significant fiber-pullout. The mode I delamination strain energy release rate of the unidirectional composites was determined using the double cantilever beam and hole in plate compression method. The DCB method indicated a significant $R$ curve effect attributed to fiber bridging while the presently available hole in plate analytical methods show questionable validity for highly anisotropic materials.
\end{abstract}

\section{INTRODUCTION}

A dichotomy exists in our predictive capabilities for laminated composite materials. The terms of the compliance matrix may be accurately predicted using laminate theory and the Halpin-Tsai equations, usually to an accuracy well within the statistical variability of fiber orientation and volume 'fraction by knowing the lay-up orientations and the material properties of the constituents (1). However, an accurate prediction of laminate strength continues to be a daunting task that has severe implications in proper part design using this class of materials. The anisotropy of unidirectional fibrous composites with a high fiber volume fraction can be quite large, with ratios of longitudinal to transverse elastic moduli of ten or more. Likewise, ratios of longitudinal to transverse strength can have values of similar magnitude. Generalized strength prediction of brittle constituent laminated composites is complicated by the pseudo-plastic, damage tolerant behavior that they often exhibit. Their pseudo-plastic behavior arises because they can often continue to carry a load after the onset of initial damage. This is due in part to the statistical variability of fiber strength, interfacial debonding between fiber and matrix, crack tip deflection and blunting, delamination, fiber bridging between crack faces, fiber pull-out from the matrix after fiber breakage, and fiber buckling during compression.
Various failure criteria have been proposed over the years to predict composite failure. The most simple of these criteria include the maximum stress and maximum strain criteria which state that failure is assumed to occur when a principle stress or strain reaches a failure threshold. The applicability of these criteria to accurately predict the onset of failure is quite poor for the general case of loading at arbitrary angles to the principal material directions. The Hill work of fracture and its subsequent expansion to the Tsai-Wu strength' criteria improved the ability to predict laminate composite strength for general loading conditions (2).

The purpose of this paper is to describe the mechanical and failure behavior of carbon fiber reinforced brittle epoxy matrix laminated composites under compressive loading at two strain rates, $10^{-3}$ and $2 \times 10^{3} 1 / \mathrm{s}$.

\section{DESCRIPTION OF MATERIAL}

The tested material consists of Hercules IM6 fibers in 3501/6 epoxy matrix. Properties of the constituents can be obtained from Hercules. The fibers are surface treated to promote bonding with the matrix and are sized to inhibit strength degradation during handling. Optical microscopy of the as-received unidirectional material is shown in figure 1. Note that the lamina stacking is not planar, but wavy. 


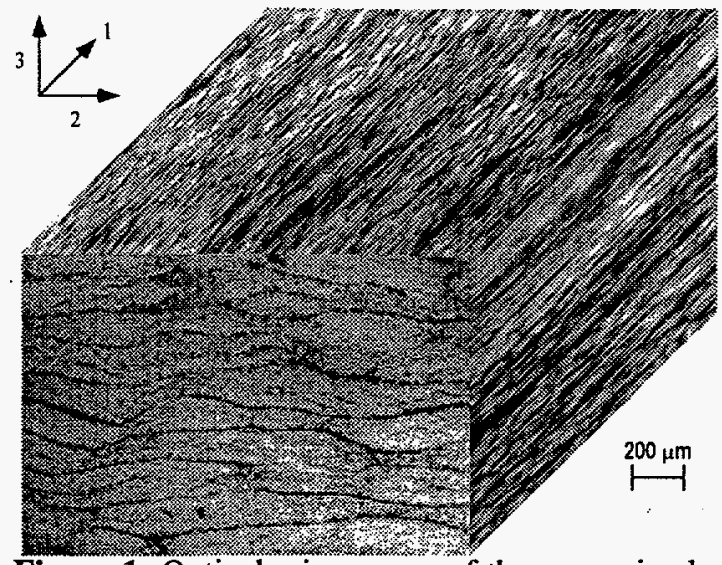

Figure 1: Optical microscopy of the as received unidirectional material. The fibers are oriented along the 1 principle direction. The laminate stacking sequence is in the 1-2 plane. The fibers appear lighter than the epoxy The laminae are stacked in a non-planar fashion. The wavy dark curves in the 3-2 plane are resin rich interlaminar regions.

\section{COMPRESSION STRAIN RATE SENSITIVITY}

Both unidirectional and quasi-isostatic laminates were tested in compression under quasistatic $\left(10^{-3} 1 / \mathrm{s}\right)$ and high $(20001 / \mathrm{s})$ strain rates. Test samples were cylinders $6.35 \times 10^{-3} \mathrm{~m}$ in length and diameter. The low strain rate tests were performed on an Instron 1125 test frame and the high strain rate tests were performed on a split Hopkinson bar machine (3). Figure 2 shows a stress-strain plot of the unidirectional lay-up illustrating the effects of the two strain rates and fiber orientation to the loading direction. The higher strain rate results in about a forty percent increase in stress-strain slope for all three orientations. The low strain to failure at the zero degree orientation is attributed to failure of the fiber precipitating catastrophic failure. The much larger strain to failure at the other two orientations are ascribed to two different mechanisms. The failure at the forty five degree fiber orientation is dominated by shear failure of the fiber-matrix interface and resulting mode II cracking. The failure at the ninety degree fiber orientation is dominated mostly by the matrix properties. Epoxy is known to have a much larger ultimate strain in compression than in tension (4).

Post mortem microscopy of the tested samples show a predominance of delamination failures between laminate stacking orientation. Figure 3 shows a scanning electron micrograph (SEM) of a high strain rate tested sample. Multiple delamination cracking in the laminate plane appeared to be a major contributor in the ultimate failure and prompted further studies into the nature of this failure mechanism.
Unidirectional IM6-3501/6 Stress-Strain

Behavior Under Compression Versus

Strain Rate and Orientation To Load

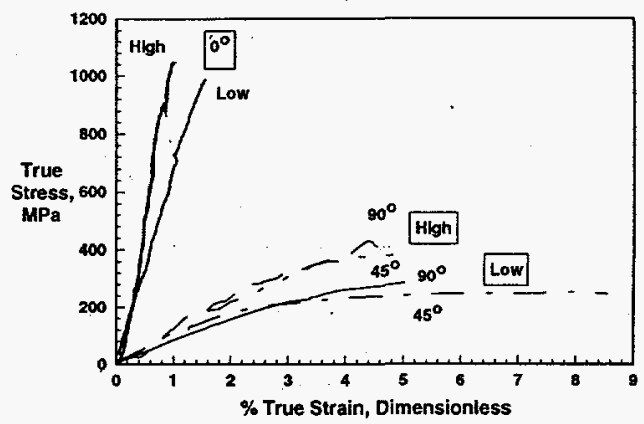

Figure 2: Comparison of strain rate and fiber orientation on the stress-strain behavior of the unidirectional stacking sequence.

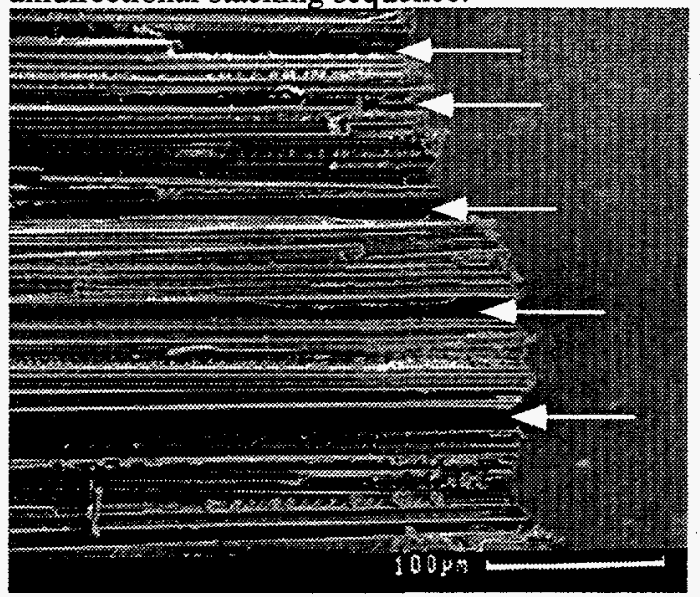

Figure 3: SEM of low strain rate compression tested unidirectional laminate. Arrows point to delamination cracks between layers. Load applied parallel to arrows.

\section{MODE I DELAMINATION STUDIES}

\section{Introduction}

Delamination in composites occurs mostly under mixed mode conditions. Delamination energies for continuous fiber reinforced laminated composites are usually much lower under mode I than mode II conditions by up to an order of magnitude. Therefore, characterization efforts should cover the entire range from mode I to mode II loading. The following section describes our efforts to characterize mode I delamination in the unidirectional material using two methods, the double cantilever beam (DCB) and the hole in plate or double cleavage drilled compression (DCDC) tests.

\section{Double Cantilever Beam Tests}

The DCB test is a standard method of determining the mode I delamination strain energy release rate (SERR) in composite 
materials (5). The DCB test has several advantages over the hole in plate method which include established analysis methods for anisotropic materials and the capability of studying steady state crack growth over much greater distances than the hole in plate method. A previous study of the DCB test determined that crack growth is stable and insensitive to end effects up to about twice the sample thickness from the end (6). However, our tests showed unstable crack growth begins about four times the sample thickness away from the end.

The samples had one side coated with aluminum in a standard vacuum evaporator to enhance contrast. Aluminum end tabs were fixed to the ends of the test specimens using a cyanocrylic ester adhesive. The tests were performed on an Instron 1125 frame at a crosshead speed of $5 \times 10^{-4} \mathrm{~m} / \mathrm{min}$. Crack growth was recorded using a high resolution video system and correlated with data acquisition computer records of time and load. Video observations of the crack growth showed the fiber bridging occurred behind the crack tip; the visible degree of which varied from sample to sample. Breakage of bridging fiber bundles resulted in expulsion of powder particles. from the crack region. Crack extension frequently occurred in - spurts of $1-3 \times 10^{-3} \mathrm{~m}$ in a couple of seconds followed by periods of negligible extension lasting 10-15 seconds.

The SERR was reduced from the experimental data using the load method and employing the Williams corrections for crack root rotation, large scale deflection, and end tab effects $(7,8)$. Figure 4 is a plot of $G_{I}{ }^{13}$ as a function of crack extension for nine tests. Each test shows significant increases in SERR as the crack extends. This contribution is attributed to fiber bridging. The contribution to SERR of fiber bridging appears to be statistical in nature and results in increases in SERR of a factor of three to five over the short crack length value. A previous report of delamination energies of laminated fiber composites did not observe $\mathrm{R}$-curve behavior in carbon fiber reinforced epoxy, although $\mathrm{R}$-curve behavior was observed in carbon fiber reinforced polyethylsulfone, and poly-ether-ether ketone (PEEK) laminated composites (9). It must be noted that notches were introduced in that study during laminate fabrication by introducing aluminum foil between laminates. Notches were machined in the present study by machining $7.6 \times 10^{-4} \mathrm{~m}$ wide notches which terminate in $\mathrm{a}<$ $90^{\circ}$ chevron. A machined notch in a material with wavy laminates like the present material is likely to force a crack that bridges two or more laminae.

SEM of fracture planes showed that fiber bridging regions are distributed fairly evenly over the crack plane. These regions are interspersed with regions where the crack propagated through resin rich areas. Figure 5 shows a SEM that combines several recurring characteristics within one image. The top region has a low particle density and is characteristic of regions where fiber bridging did not occur. The long narrow middle plateau is a resin rich area where the crack did not extend along the fiber-matrix interface. The resin rich areas can have dimensions of up to $1-2 \times 10^{-3} \mathrm{~m}$ on a side. The lower region of the figure is where extensive fiber bridging occurred. These regions are always observed with high densities of powder epoxy particles.

\section{Mode I Fracture Energy Versus Crack Extension - R Curve Dependence}

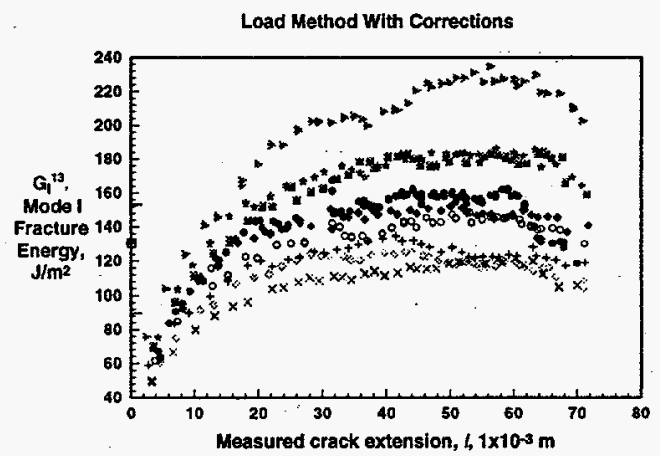

Figure 4: $G_{l}^{1 s}$ versus crack extension for the unidirectional material determined by the DCB method. Note R-curve behavior.

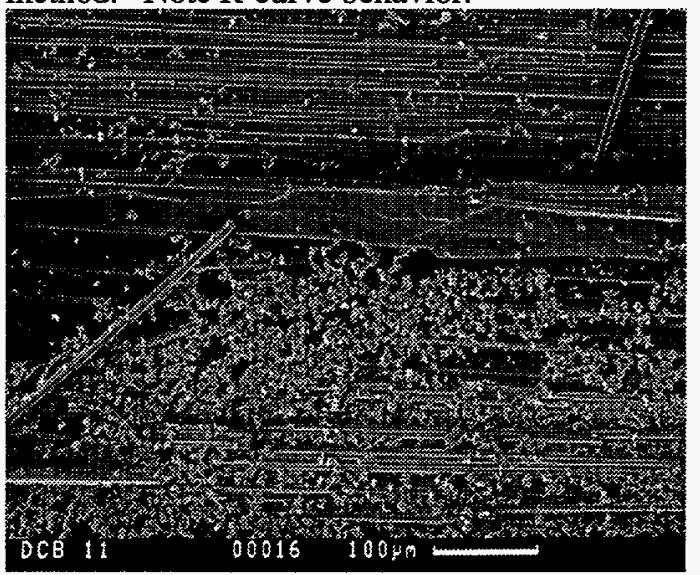

Figure 5: SEM of DCB crack plane.

\section{Hole In Plate Tests}

The hole in plate compression sample was selected as an alternative testing configuration to confirm the validity of the DCB tests. It has previously been used to study the mode I failure of brittle porous solids (10). Recent finite element analyses have refined the calibration of the method for isotropic materials (11). The specimen geometry employed had a hole radius of $7.9 \times 10^{-4}$ $\mathrm{m}$, a half width of $3.18 \times 10^{-3} \mathrm{~m}$, and overall length of $3.8 \times 10^{-2} \mathrm{~m}$. Two orientations were tested to determine the strain energy release rate parallel and normal to the laminate plane. The samples had one surface normal to the hole longitudinal axis coated with aluminum using a standard vacuum evaporator to enhance contrast. The sample ends were covered with PTFE tape 
(plumber's tape) to minimize friction with the loading plattens. One-dimensional compression loading was applied using an Instron 1125 mechanical test frame at a crosshead speed of $1 \times 10^{-4} \mathrm{~m} / \mathrm{min}$. This loading results in tensile stresses at the hole surface with a magnitude of about 1/3 the applied compression stress for isotropic materials. Crack growth was recorded using a high resolution video system and correlated with data acquisition computer records of time and load. Stable crack growth was observed for only about $6 \times 10^{-3} \mathrm{~m}$ from the hole edge in the $G_{I}{ }^{13}$ tests and for about $8.5 \times 10^{-3} \mathrm{~m}$ in the $G_{I}^{12}$ samples.

The data was reduced using two analytical methods $(10,11)$. Conversion from the stress intensity factor to a SERR was accomplished using a empirically modified effective modulus $(12,13)$

These two analyses are compared in figure 6 for the unidirectional composite. Both methods do not provide physically realistic results compared with the DCB method $G_{l}$, although the He \& Evans analysis is somewhat better than the Sammis \& Ashby analysis. The inaccuracy of these analytical methods is attributed to the assumption of isotropy in their derivation. The complex stress state surrounding the hole probably invalidates these analyses for highly anisotropic materials.

\section{Hole In Plate Mode I Delamination Tests}
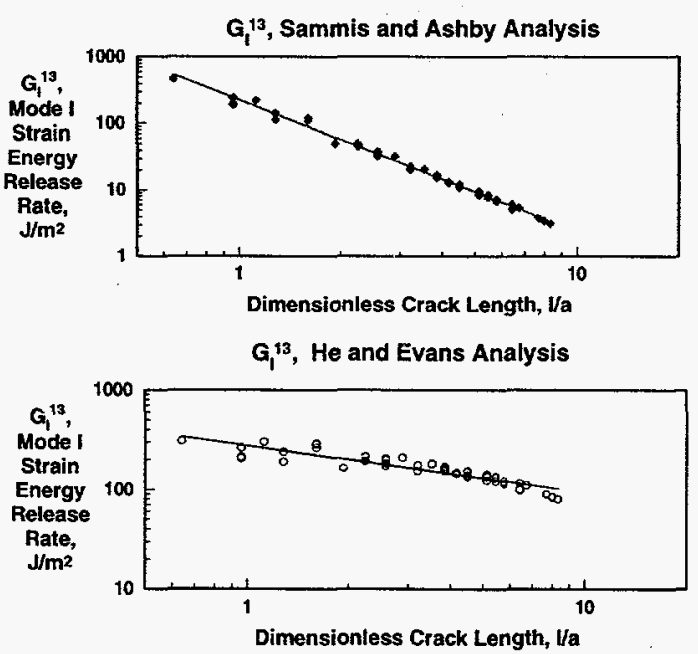

Figure 6: Comparison of two analyses for the hole in plate tests.

The two analytical approaches for determining the SERR has been used to compare the ratio of release rates $G_{I}^{I 2} / G_{I}^{I 3}$ for the unidirectional material. Both analytical methods indicate that $G_{I}{ }^{12}$ is about fifty percent higher than the delamination $G_{I}{ }^{13}$.

\section{CONCLUSIONS}

The IM6 fiber - 3501/6 epoxy resin unidirectional laminated composite showed a forty percent increase in the stress-strain slope under compressive loading at a strain rate of 2000 $1 / \mathrm{s}$ than at $1 \times 10^{-3} 1 / \mathrm{s}$ when the applied load was parallel, forty five degrees, and normal to the fiber axis. The compression tests showed that delamination was a significant failure component. The mode I delamination energy $G_{I}{ }^{13}$ was determined using the DCB and hole in plate tests. The DCB test showed a significant but statistical R-curve behavior that is attributed to fiber bridging behind the crack tip. Both analysis methods employed in the hole in plate tests indicated a decreasing SERR with increasing crack length although fiber bridging was visibly observed in the hole in plate tests. The applicability of current hole in plate analytical methods to highly anisotropic materials is there questionable. Both hole in plate analytical methods indicate that $G_{I}{ }^{12}$ is about fifty percent higher than $G_{I}^{13}$.

\section{ACKNOWLEDGMENTS}

This work was sponsored by the DoD/DOE Joint Munitions Technology Program. Manual Lovato is thanked for assistance in sample preparation. Robert Carpenter is thanked for performing the Hopkinson bar tests, and Mike Lopez is thanked for performing the quasistatic compression tests.

\section{REFERENCES}

1. Halpin, J. C., Primer on Composite Materials Analysis, (Technomic Publishing Company, Inc., Lancaster, 1992).

2. Tsai, Stephen W. and Edward M. Wu, Journal of Composite Materials, 5, 58 (January 1971).

3. Follansbee, P. S., in Metals Handbook (American Society of Metals, Metals Park, OH., 1985), Vol. 8, p. 198.

4. Hull, D., Introduction To Composite Materials, (Cambridge University Press, Cambridge, 1981).

5. Whitney, J. M., C. E. Browning, and W. Hoogsteden, Journal of Reinforced Plastics and Composites, 1, 297 (October 1982).

6. Kanninen, M. F., International Journal of Fracture, 9, 83 (1973).

7. Williams, J. G., Journal of Strain Analysis, 24, 207 (1989).

8. Williams, J. G., Composite Science and Technology, 35, 367 (1989).

9. Hashemi, S., A. J. Kinloch, and J. G. Williams, Proceedings of the Royal Society of London, $\mathbf{A}$ 427, 173 (1990).

10. Sammis, C. G., and M. F. Ashby, Acta Metallurgica, 34, 511 (1986).

11. He, Ming Y., Michelle R. Turner, and Anthony G. Evans, Acta Metallurgica et Materialia, Submitted September 1994.

12. Sih, G. C., P. C. Paris, and G. R. Irwin, International Journal of Fracture, 1, 189 (1965).

13. Wells, J. K., and P. W. R. Beaumont, Journal of Materials Science, 22, 1457 (1987). 